\title{
Long-term programming of blood pressure by maternal dietary iron restriction in the rat
}

\author{
Rohan M. Lewis $^{1 *}$, Alison J. Forhead ${ }^{2}$, Clive J. Petry ${ }^{1}$, Susan E. Ozanne ${ }^{1}$ and C. Nicolas Hales ${ }^{1}$ \\ ${ }^{1}$ Department of Clinical Biochemistry, University of Cambridge, Addenbrooke's Hospital, Cambridge CB2 2QR, UK \\ ${ }^{2}$ Department of Physiology, University of Cambridge, Downing Street, Cambridge CB2 3EG, UK
}

(Received 23 July 2001 - Revised 14 March 2002 - Accepted 24 April 2002)

\begin{abstract}
We have reported that blood pressure was elevated in 3-month-old rats whose mothers were Fe-restricted during pregnancy. These animals also had improved glucose tolerance and decreased serum triacylglycerol. The aim of the present study was to determine whether these effects of maternal nutritional restriction, present in these animals at 3 months of age, can be observed in the same animals in later life. Pulmonary and serum angiotensin converting enzyme (ACE) concentrations were also measured to investigate whether the renin-angiotensin system was involved in the elevation of blood pressure observed in the offspring of Fe-restricted dams. Systolic blood pressure was higher in the offspring of Fe-restricted dams at 16 months of age. Heart and kidney weight were increased as a proportion of body weight in the offspring of Fe-restricted dams. The pulmonary ACE concentration was not significantly different between the groups. The serum ACE concentration was significantly elevated in the offspring of Fe-restricted dams at 3 but not 14 months of age. There was a strong correlation between serum ACE levels at 3 and 14 months of age. Glucose tolerance and serum insulin were not different between the maternal diet groups. Serum triacylglycerol tended to be lower in the offspring of Fe-restricted dams. There were no differences in serum non-esterified fatty acids or serum cholesterol between the maternal diet groups. This study provides further evidence that maternal nutrition has effects on the offspring that persist throughout life. At 16 months of age, the elevation of blood pressure in Fe-restricted offspring does not appear to be mediated via changes in ACE levels. Both cardiac hypertrophy and decreased serum triacylglycerol have also been observed in Fe-restricted fetuses, suggesting that these changes may be initiated in utero.
\end{abstract}

Maternal iron deficiency: Growth retardation: Blood pressure: Triacylglycerol

Birth weight in human subjects is inversely associated with blood pressure in adult life (Law \& Shiell, 1996). Studies of fetal growth restriction in animal models have also shown this relationship. In rats, blood pressure has been found to be elevated in growth-restricted offspring as a result of both maternal nutritional insults (Langley \& Jackson, 1994; Crowe et al. 1995; Woodall et al. 1996; Lewis et al. 2001b) and pharmacological insults (Benediktsson et al. 1993; Lindsay et al. 1996; Langley-Evans, 1997). These studies provide models in which to investigate the mechanisms underlying this phenomenon. To date, the majority of animal studies have investigated the effects of early growth restriction in younger adult offspring.

The molecular mechanisms underlying programming are not well understood. One of the main theories involves effects on the fetal hypothalamic-pituitary-adrenal axis. Fetal steroid exposure has been shown to cause elevated blood pressure in the offspring, and offspring of proteinrestricted rats have been shown to have altered expression of components of the hypothalamic-pituitary-adrenal axis (Benediktsson et al. 1993; Bertram et al. 2001). Another possible mechanism for the initiation of hypertension following intra-uterine stress is that there are structural abnormalities in the kidneys of the growth-restricted offspring (Marchand \& Langley-Evans, 2001). There is also evidence in the offspring of protein-restricted rats that the renin-angiotensin system is involved in the pathogenesis of the high blood pressure seen in that model (LangleyEvans et al. 1999a).

\footnotetext{
Abbreviation: ACE, angiotensin converting enzyme.

* Corresponding author: Dr Rohan M. Lewis, present address, FOAD Research Division, University of Southampton, Level F, Princess Ann Hospital, Mail point 815, Coxford Road, Southampton SO17 5YA, UK, fax +44 238078 6933, email rml2@ soton.ac.uk
} 
We have previously reported elevated blood pressure in the 3-month-old offspring of Fe-restricted dams (Lewis et al. 2001b). These animals were also found to have decreased serum triacylglycerol, improved glucose tolerance, were growth restricted at birth and remained smaller to 3 months of age. Elevated blood pressure has also been reported in the offspring of Fe-restricted dams at $40 \mathrm{~d}$ of age (Crowe et al. 1995). These findings are similar to those observed in the maternal low-protein model in which blood pressure is elevated (Langley et al. 1994; Langley \& Jackson, 1994), triacylglycerol decreased (Lucas et al. 1996) and glucose tolerance improved in younger animals (Shepherd et al. 1997). This suggests that common underlying mechanisms may initiate the long-term effects of maternal environment on the offspring.

In the offspring of protein-restricted dams, changes in the activity of the renin-angiotensin system are thought to be involved in the development of high blood pressure. Evidence for this includes increased levels of pulmonary and serum angiotensin converting enzyme (ACE) in the offspring of protein-restricted dams (Langley-Evans \& Jackson, 1995; Langley \& Jackson, 1994) and the fact that postnatal treatment with ACE inhibitors prevents the development of high blood pressure in these animals (Sherman \& Langley-Evans, 1998; Vehaskari et al. 2001). If, as we have suggested, there are similarities between these models, then components of the reninangiotensin system may also mediate the elevated blood pressure in the maternal Fe restriction model.

The pulmonary vasculature is the major site of ACE activity and the systemic conversion of angiotensin I to angiotensin II. However, ACE is also important in a variety of other tissues for the regulation of local renin-angiotensin systems, which independently regulate blood flow through specific tissues. While pulmonary ACE plays the major role in the regulation of blood pressure, local tissue renin-angiotensin systems will also contribute vascular resistance and blood pressure. Serum ACE concentration is derived from proteolytic cleavage of endothelial ACE (Santhamma \& Sen, 2000). Although serum ACE is unlikely to have a major physiological effect on blood pressure serum levels may reflect overall levels of tissue ACE in the whole animal.

The aim of the present study was to investigate whether effects of maternal $\mathrm{Fe}$ deficiency on blood pressure, glucose tolerance and plasma lipids seen in these offspring at 3 months of age are present in the same animals later in life. Pulmonary and serum ACE concentration was measured to investigate whether there were changes in ACE concentration that might underlie the observed differences in blood pressure between the groups.

\section{Methods \\ Animals}

All animal procedures were performed, under licence, in accordance with the UK Animals (Scientific Procedures) Act (1986). Virgin Wistar females were housed individually and maintained at $22^{\circ} \mathrm{C}$. They were fed either control
(K4447.01) or Fe-restricted diets (K4447.00; Hope Farms, Worden, Holland) ad libitum and provided with deionised water. The control diet was made by adding $150 \mathrm{mg} \mathrm{Fe}$ as iron subcarbonate/kg to the Fe-restricted diet, so that in all other respects the two experimental diets were identical. The trace level of $\mathrm{Fe}$ in the Fe-restricted diet was $3 \mathrm{mg} / \mathrm{kg}$. The diets contained $(/ \mathrm{kg}) 175 \mathrm{~g}$ crude protein $(\mathrm{N} \times 6.25), 52 \mathrm{~g}$ crude fat, $662 \mathrm{~g}$ sugar and starch, with a gross energy content of $16 \cdot 6 \mathrm{MJ} / \mathrm{kg}$. The LAD 1 maintenance diet contained/kg: $196 \mathrm{~g}$ crude protein $(\mathrm{N} \times 6.25)$, $33 \mathrm{~g}$ crude fat, $491 \mathrm{~g}$ sugar and starch, $138 \mathrm{mg} \mathrm{Fe}$, with a gross energy content of $15.7 \mathrm{MJ} / \mathrm{kg}$ (Special Diet Services, Witham, Essex, UK).

Prior to the present study, rats were fed LAD 1 diet. One week prior to mating, dams were placed onto either the control diet or the Fe-restricted diet. After $7 \mathrm{~d}$ on the diet, dams were mated; those that did not mate within $4 \mathrm{~d}$ were excluded from the present study. Dams were maintained on the control or Fe-restricted diet throughout gestation. On the day of birth, dams on the Fe-restricted diet were transferred to the control diet. To standardise conditions, litters were culled to eight on postnatal day 3. At $21 \mathrm{~d}$ of age, two male and two female offspring from each litter were weaned onto LAD 1. Of the eleven control litters and ten Fe-restricted litters started on the diets, eight control litters and six Fe-restricted litters were bred successfully. Unfortunately, in one of the Fe-restricted litters four females were kept rather than two males and two females. As the studies reported in the present paper concern the older offspring, there were a number of deaths before the experiments were conducted. These deaths were not clustered in offspring from any particular litter and although in two litters two of the four rats did die, in each case a male and a female remained alive. As such, at least one of the original two males and females from each of the original litters was included in the analysis of blood pressure, glucose tolerance and serum lipids. By the time post mortems were carried out on remaining animals at 18 months of age, each group contained male and female representatives from at least five different litters.

As described previously, there was reduced maternal weight gain in the Fe-restricted dams (maternal weight on day 22 of gestation control 437 (SD 26) $v$. Fe-restricted 385 (SD 12) $\mathrm{g}$ and reduced maternal food intake during gestation (87 (SD 4) v. 70 (SD 3) g/d respectively) (Lewis et al. 2001b). Both the Fe-restricted dams and their offspring were anaemic compared with the controls (Lewis et al. 2001b). Litter size was not significantly different between the groups $(15 \cdot 1$ (SD 2.4) v. $13 \cdot 5$ (SD 1.1)).

\section{Glucose tolerance tests}

Glucose tolerance was measured and blood collected for serum lipid and insulin analysis in the control males and females at 402 (SD 2) d (14 months) and in the maternal Fe-restricted males and females at 401 (SD 2) d (14 months) of age. Glucose tolerance tests were performed on conscious rats after an overnight fast (18 h). Fasting glucose was measured from tail blood using a HemoCue Glucose Analyser (HemoCue, Sheffield, South Yorkshire, $\mathrm{UK})$ and then $10 \mathrm{ml}$ glucose $(100 \mathrm{~g} / \mathrm{l} \quad 0 \cdot 15 \mathrm{M}-\mathrm{NaCl}) / \mathrm{kg}$ 
was administered by intraperitoneal injection. Glucose levels were then measured at 15, 30, 60, 120 and $180 \mathrm{~min}$ after the injection.

\section{Serum insulin and lipid measurements}

Fasting serum was collected prior to the glucose tolerance test and stored at $-80^{\circ} \mathrm{C}$ prior to analysis. Serum insulin was measured using a rat insulin ELISA kit (DRG International, Mountainside, NJ, USA) according to the manufacturer's instructions. All samples were assayed in duplicate.

Serum lipids were measured enzymatically using a Monarch auto-analyser (Instrumentation Laboratories, Lexington, MA, USA). Fasting serum non-esterified fatty acids were measured using the Free Fatty Acids, Halfmicro test (catalogue no. 1383 175; Boheringer Mannheim, Mannheim, Germany). Fasting serum triacylglycerol was measured using GPO trinder reagents (catalogue no. 337-A; Sigma Diagnostics, St Louis, MO, USA). Fasting serum cholesterol was measured using Infinity cholesterol reagent (catalogue no. 401-25P; Sigma Diagnostics).

\section{Blood pressure measurement}

Blood pressure was measured in the male offspring of control dams at 449 (SD 14) d (16 months) of age, in the female offspring of control dams at 459 (SD 4) d (16 months) of age, in the male offspring of Fe-restricted dams at 458 (SD 2) d (16 months) of age and in the female offspring of Fe-restricted dams at 458 (SD 2) d (16 months) of age. Blood pressures were recorded using the indirect tail-cuff method. Rats were placed in perspex restraining-tubes and acclimatised in a warmed chamber $\left(27-29^{\circ} \mathrm{C}\right)$. Five systolic blood pressure recordings were made from each rat. Blood pressure was read from the traces by another investigator who was blind to the maternal diet group and gender of the rat. The highest and lowest blood pressure readings were excluded and the mean value calculated from the remaining three values. To assess the repeatability of the results, one female and one male rat had blood pressures recorded on five separate occasions. The intra-assay $\mathrm{CV}$ for the male rat was $6.2 \%$ and for the female rat $3.2 \%$.

Originally there were sixteen male and sixteen female offspring from eight control litters and ten male and fourteen female offspring from six Fe-restricted litters (in one Fe-restricted litter there were no male offspring and four females were kept instead), however animals started to die at about 12 months of age. At about 18 months of age, the remaining animals were killed by $\mathrm{CO}_{2}$ inhalation and post mortems conducted. There were five male offspring of control dams, killed at 510 (SD 15) d of age, twelve female offspring of control dams killed at 530 (SD 15) d of age; five male offspring of Fe-restricted dams killed at 507 (SD 24) d of age and eight female offspring of Fe-restricted dams killed at 516 (SD 26) d of age. At post mortem, animals were weighed and nose to base-oftail length was measured. Hearts, lungs, livers and kidneys were dissected out and weighed. Lung tissue was collected and frozen in liquid $\mathrm{N}_{2}$ and stored at $-80^{\circ} \mathrm{C}$ prior to analysis.

\section{Angiotensin converting enzyme assay}

ACE concentrations were measured in lung tissue collected at post mortem and in serum collected from the same animals at 3 and 14 months of age. Tissue and serum ACE concentration was determined by a spectrophotometric assay based on the conversion of hippuryl-L-histidyl-Lleucine-L to hippurate by ACE as described previously (Forhead et al. 2000), using $50 \mathrm{mg}$ lung tissue or $25 \mu \mathrm{l}$ serum. Addition of captopril to the incubation mixture abolished the ACE-induced production of hippurate. Tissue ACE concentration was expressed as hippurate (nmol) generated/min per $\mathrm{mg}$ protein while plasma levels are expressed in units/l where 1 unit is equivalent to $1 \mu \mathrm{mol}$ hippurate generated/min. The inter- and intraassay CV for this assay were $3.65 \%$ (n 10 assays) and $8.9 \%$ ( $n 15$ assays) respectively. Tissue protein content was measured in the original homogenate by the Lowry method (Lowry et al. 1951).

\section{Statistical analysis}

Data were analysed using two-way ANOVA to investigate effects of maternal diet and the gender of the offspring. Where the data were not normally distributed they were analysed using the Friedman test where the ANOVA is performed on ranked data. To investigate whether differences in body weight were influencing the results, analyses were also performed with body weight included as a covariate. As the data have been analysed by two-way ANOVA, where significant differences are indicated they refer to differences between either the maternal diet groups or between the two genders. Data are presented as mean values and standard deviations, except where the data were abnormally distributed, in which case the data are presented as median values and interquartile ranges. In graphs, data are presented as box plots, which show the median, interquartile range and extreme values. Correlations were performed using the Pearson correlation coefficient.

\section{Results}

There were no apparent differences in the survival of the offspring between the maternal diet groups (results not shown) and in both maternal diet groups the offspring started to die at about 1 year of age. At 14 months of age, the offspring of Fe-restricted dams were lighter than the offspring of control dams and males were heavier than females in both groups $(P<0 \cdot 001$, Table 1$)$.

\section{Blood pressure and glucose tolerance}

Blood pressure was higher in the offspring of Fe-restricted dams than in controls $(P<0.05$, Fig. 1), but was not significantly different between genders.

Fasting blood glucose in the offspring was not different between the maternal diet groups or genders (Table 1). 
Glucose tolerance, as measured by area under the glucose tolerance curve, was not different between the maternal diet groups, but was better in females than in males $(P<0 \cdot 05$, Table 1). Adjusting for current body weight did not affect the outcome of this analysis.

\section{Serum insulin and lipids}

Fasting serum insulin in the offspring was not significantly different between the maternal diet groups but was lower in females than males $(P<0 \cdot 05$, Table 1$)$.

Serum triacylglycerol concentrations were lower in the offspring of Fe-restricted dams $(P=0.055$, Table 2$)$, but there was no significant difference between genders. Fasting serum cholesterol in the offspring was not different between the maternal diet groups, but was lower in females than in males $(P<0 \cdot 05$, Table 2$)$. Fasting serum non-esterified fatty acids in the offspring were not different between the groups but were higher in females than males $(P<0.05$, Table 2). If the analysis was performed including body weight as a covariate this eliminated the gender differences for cholesterol and non-esterified fatty acids.

\section{Post mortem data}

At about 18 months of age, post mortems were performed on surviving animals. Post mortem body weights were lower in the offspring of Fe-restricted dams than in the offspring of controls $(P<0 \cdot 01)$ and were also lower in females than in males $(P<0.001$, Table 3$)$. Heart weight as a percentage of body weight was increased in the offspring of Fe-restricted dams $(P<0 \cdot 01$, Table 3$)$ and was greater in females than males $(P<0 \cdot 005$, Table 3$)$. Kidney weight as a percentage of body weight was greater in the offspring of Fe-restricted dams $(P<0 \cdot 05$, Table 3$)$, but was not different between genders. Liver weight as a percentage

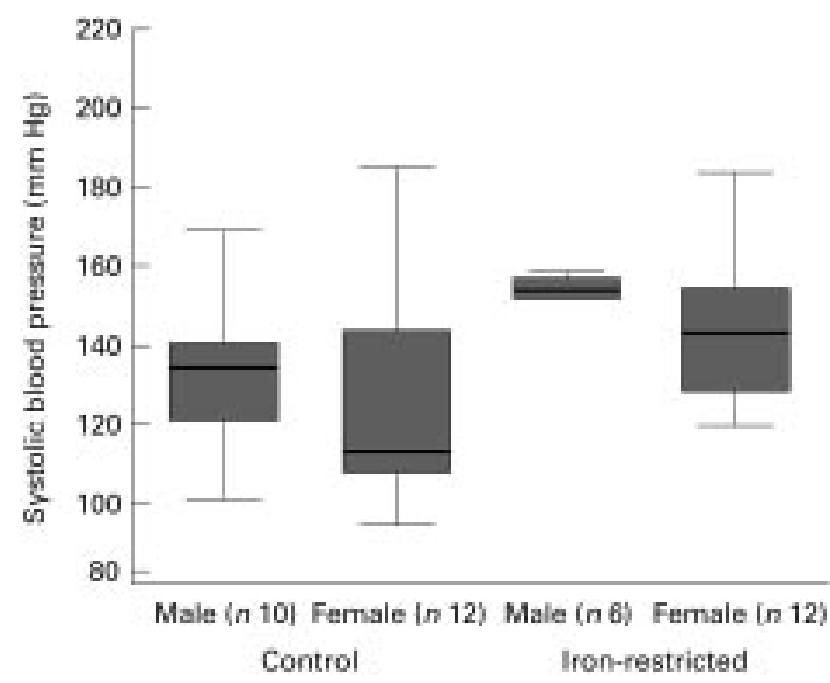

Fig. 1. Systolic blood pressure in the offspring of control and ironrestricted dams at 16 months of age. Values are medians and interquartile ranges (box) with extreme values (whiskers). For details of diets and procedures, see p. 284. There was a significant effect $(P<0.05)$ of maternal diet, indicating that the offspring of iron-restricted dams had higher blood pressures than those of control dams. 
Table 2. Fasting serum lipids (mmol/l) in 14-month-old offspring of control and iron-restricted dams*

(Median values and interquartile ranges)

\begin{tabular}{|c|c|c|c|c|c|c|c|c|c|c|c|}
\hline & \multicolumn{4}{|c|}{ Control } & \multicolumn{4}{|c|}{ Iron-restricted } & & & \\
\hline & \multicolumn{2}{|c|}{ Male } & \multicolumn{2}{|c|}{ Female } & \multicolumn{2}{|c|}{ Male } & \multicolumn{2}{|c|}{ Female } & \multicolumn{3}{|c|}{$\begin{array}{l}\text { Statistical significance of effect } \\
\text { (two-way ANOVA) }\end{array}$} \\
\hline & Median & IQR & Median & IQR & Median & IQR & Median & IQR & Maternal diet & Gender & Interactior \\
\hline Triacylglycerol & $6 \cdot 0$ & $2 \cdot 7-9 \cdot 2$ & $2 \cdot 7$ & $2 \cdot 0-5 \cdot 2$ & $2 \cdot 8$ & $1 \cdot 9-4 \cdot 3$ & 1.4 & $1 \cdot 2-3 \cdot 6$ & $P<0.055$ & NS & NS \\
\hline $\begin{array}{l}\text { Non-esterified } \\
\text { fatty acids }\end{array}$ & $1 \cdot 2$ & $1 \cdot 0-1 \cdot 3$ & 1.4 & $1.3-1.5$ & $1 \cdot 3$ & $1 \cdot 1-15$ & 1.4 & $1.3-1.7$ & NS & $P<0.05$ & NS \\
\hline Cholesterol & 9.9 & $5 \cdot 4-11 \cdot 1$ & $4 \cdot 2$ & $3 \cdot 8-7 \cdot 5$ & $5 \cdot 3$ & $5 \cdot 1-6 \cdot 8$ & $4 \cdot 0$ & $3 \cdot 1-5 \cdot 7$ & NS & $P<0.05$ & NS \\
\hline
\end{tabular}

IQR, interquartile range.

${ }^{*}$ For details of diets and procedures, see p. 284.

Table 3. Post mortem weight, volume and organ weights as a percentage of body weight in the offspring of control and iron-restricted dams at 18 months of age (Mean values and standard deviations)

\begin{tabular}{|c|c|c|c|c|c|c|c|c|c|c|c|}
\hline & \multicolumn{4}{|c|}{ Control } & \multicolumn{4}{|c|}{ Iron-restricted } & & & \\
\hline & \multicolumn{2}{|c|}{ Male $(n 5)$} & \multicolumn{2}{|c|}{ Female ( $n$ 12) } & \multicolumn{2}{|c|}{ Male ( $n 5)$} & \multicolumn{2}{|c|}{ Female $(n 8)$} & \multicolumn{3}{|c|}{$\begin{array}{l}\text { Statistical significance of effect } \\
\text { (two-way ANOVA) }\end{array}$} \\
\hline & Mean & SD & Mean & SD & Mean & SD & Mean & $\mathrm{SD}$ & Maternal diet & Gender & Interaction \\
\hline Body weight (g) & 821 & 104 & 523 & 115 & 698 & 127 & 395 & 83 & $P<0.01$ & $P<0.001$ & NS \\
\hline Length $(\mathrm{cm})$ & $28 \cdot 6$ & 0.4 & 24.4 & 0.9 & 28 & 1.1 & 23.6 & $1 \cdot 1$ & NS & $P<0.01$ & NS \\
\hline Heart (\% BW) & 0.25 & 0.04 & 0.29 & 0.04 & 0.30 & 0.03 & 0.40 & 0.08 & $P<0.01$ & $P<0.005$ & NS \\
\hline Liver (\% BW) & 3.38 & 0.51 & $4 \cdot 19$ & 0.38 & 3.78 & 0.21 & 4.84 & 1.22 & NS & $P<0.005$ & NS \\
\hline Kidney (\%BW) & 0.76 & 0.24 & 0.73 & 0.12 & 1.01 & 0.12 & 0.89 & 0.29 & $P<0.05$ & NS & NS \\
\hline Lung (\% BW) & 0.39 & 0.04 & 0.44 & 0.05 & 0.41 & 0.07 & 0.50 & 0.12 & NS & NS & NS \\
\hline
\end{tabular}

BW, body weight.

${ }^{*}$ For details of diets and procedures, see p. 284 


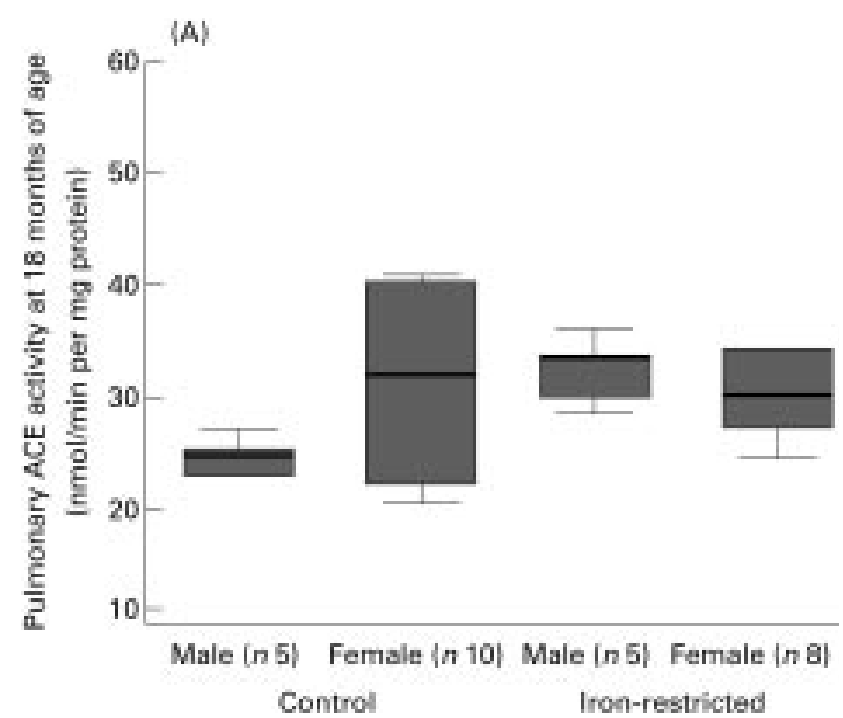

(B)
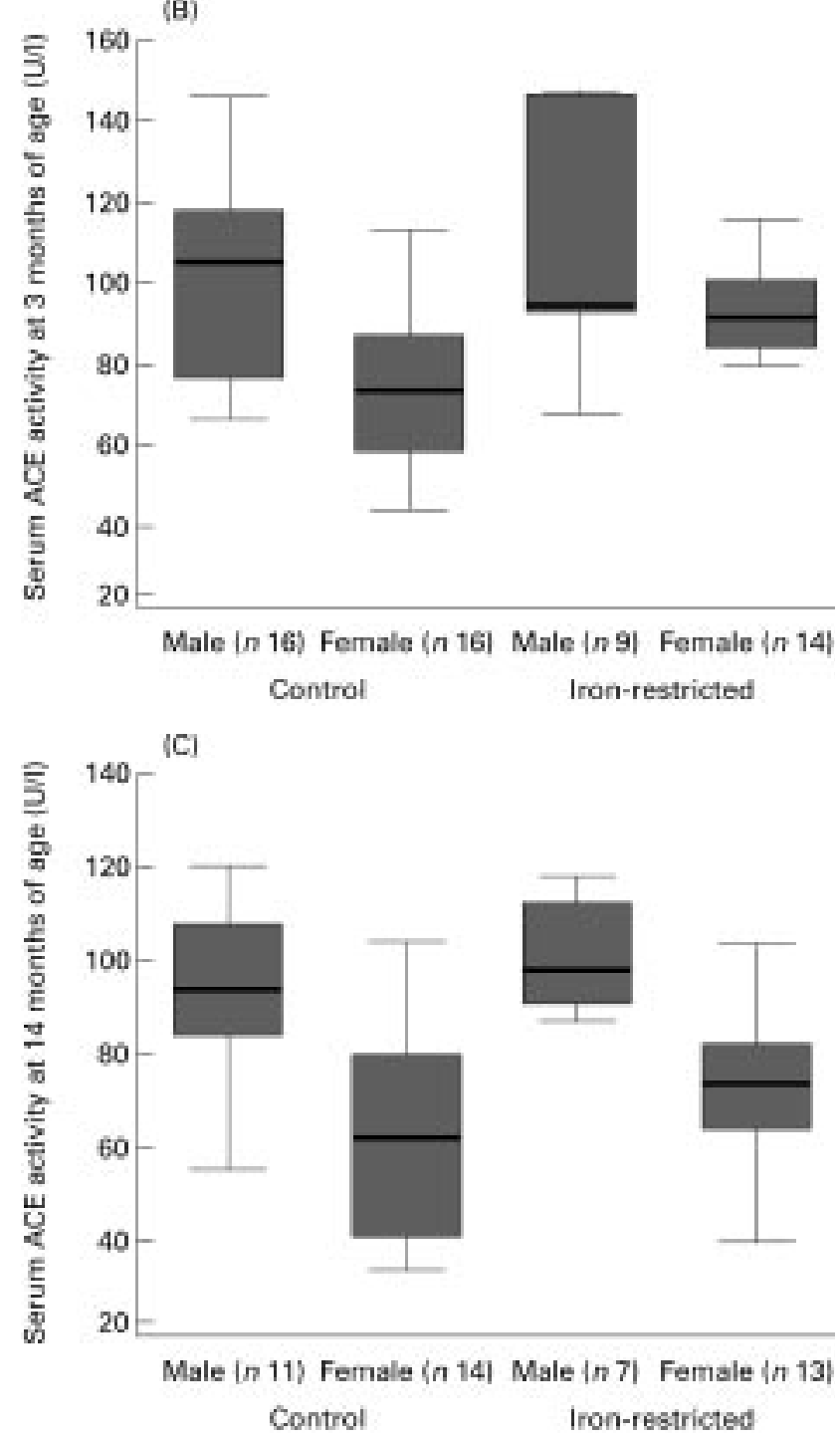

of body weight was not different between the maternal diet groups, but was higher in females than in males $(P<0.005$, Table 3). Lung weight as a percentage of body weight was not significantly different between the maternal diet groups or with gender.

\section{Angiotensin onverting enzyme results}

Pulmonary ACE in the offspring at 18 months of age was not significantly different between the groups (Fig. 2(A)). Pulmonary ACE concentrations in the offspring at 18 months of age was not correlated with blood pressure at either 3 or 14 months of age. Pulmonary ACE concentrations at 18 months of age were significantly correlated with serum ACE concentration in the female offspring of Fe-restricted dams at 14 months of age $(r 0.85, n 7$, $P<0.01)$, but not in any of the other groups, nor in any group at 3 months of age. Serum ACE concentrations were increased in the Fe-restricted offspring at 3 months of age $(P<0.05$, Fig. 2(B)), but there were no significant differences at 14 months of age (Fig. 2(C)). Serum ACE concentrations were correlated at 3 and 14 months of age in all the groups combined $(r 0.83, n 45, P<0.001)$ and in each of the four individual groups. Serum ACE concentration was not significantly correlated with blood pressure at 3 months of age. At 14 months of age there was a negative correlation between serum ACE concentration and blood pressure in both the control males $(r-0 \cdot 67, n$ $10, P<0.05)$ and females $(r-0.60, n 12, P<0.05)$, but there were no significant correlations with blood pressure in the Fe-restricted offspring.

\section{Discussion}

The present study demonstrates that maternal diet and specifically maternal Fe restriction can affect the offspring's physiology and metabolism throughout life. At 3 months of age, the offspring of Fe-restricted dams had elevated blood pressure, decreased serum triacylglycerol and decreased body weight (Lewis et al. 2001b). That these effects were still evident at an age at which the animals were beginning to die of natural causes demonstrates that they are a permanent adaptation to maternal nutrient restriction.

The finding that blood pressure is elevated in the 16-month-old offspring of Fe-restricted dams reflects our previous findings in these animals at 3 months of age (Lewis et al. 2001b) and those of Crowe et al. (1995) in $40 \mathrm{~d}$ old rats. These studies demonstrate that the elevation of blood pressure in the offspring of Fe-restricted rats,

Fig. 2. (A) Pulmonary angiotensin converting enzyme (ACE) concentrations at 18 months of age, (B) serum ACE concentration at 3 months of age, (C) serum ACE concentration at 14 months of age. Serum ACE levels were elevated in the offspring of iron-restricted dams at 3 months of age $(P<0.05)$. At both 3 and 14 months of age serum ACE was lower in females than males $(P<0.05)$. Values are medians and interquartile ranges (box) with extreme values (whiskers). For details of diets and procedures, see p. 284. 
which is initiated between 20 and $40 \mathrm{~d}$ postnatally, is a permanent adaptation in response to maternal Fe restriction.

The offspring of protein-restricted dams also have elevated blood pressure and this may be due to effects on their renin-angiotensin systems (Sherman \& LangleyEvans, 2000; Vehaskari et al. 2001). Both serum and pulmonary ACE levels have been reported to be elevated in the offspring of protein-restricted dams (Langley-Evans \& Jackson, 1995). There were no differences in pulmonary ACE activity in the offspring of Fe-restricted dams at 18 months of age. There was a small rise in serum ACE levels at 3 , but not 14, months of age. However, there was no correlation between blood pressure and serum ACE at 3 months of age. At 14 months of age, serum ACE concentration was negatively correlated with blood pressure in both male and female controls. It does not appear, therefore, that there is a direct effect of either pulmonary or serum ACE on blood pressure in these animals. However, as serum ACE levels have been found to be elevated in 13-week-old offspring of proteinrestricted dams, the elevation in serum ACE at 3 months of age may represent another similarity between the maternal low-protein and maternal Fe-restriction models (Langley-Evans \& Jackson, 1995). It is also possible that there were changes in local regulation of the reninangiotensin system, and that changes in other components of the renin-angiotensin system, such as angiotensin receptors, may contribute to the elevated blood pressure in this model. Future experiments could look at renin and angiotensin II concentrations as well as investigating the expression of the ACE and the angiotensin receptor in different tissues.

It is also interesting that serum ACE levels in young adults correlate with those observed in later life. In human subjects, the ACE genotype accounts for $47 \%$ of the variation in serum ACE levels (Rigat et al. 1990) and it is possible that genetic differences could explain this finding.

Heart weight, as a proportion of body weight, in the offspring of Fe-restricted dams has been reported to be elevated in the fetus, postnatally at 20 and $40 \mathrm{~d}$ of age, as well as at 18 months of age in the present study (Crowe et al. 1995; Lewis et al. 2001a). Similarly, although kidney weight as a proportion of body weight was not elevated in the fetuses of Fe-restricted dams, it was elevated at 20 and $40 \mathrm{~d}$ of age and was elevated at 18 months of age in these rats (Crowe et al. 1995; Lewis et al. 2001a). This indicates that the cardiac and renal hypertrophy seen in these animals originates very early in life and may precede the elevation in blood pressure, which is not apparent at $20 \mathrm{~d}$ of age (Crowe et al. 1995). While it is unclear whether these changes in cardiac and renal size either contribute to, or occur as a result of, the hypertension in the offspring of Fe-restricted dams, it is interesting to see these changes in systems intimately involved in the control of blood pressure. These findings with regard to organ weight are in contrast to the lowprotein model where there is no consistent effect on heart or kidney weight (Desai et al. 1996; Langley \& Jackson, 1994).

As we have previously demonstrated in the Fe-restricted fetus, and in these animals at 3 months of age (Lewis et al. $2001 a, b)$, serum triacylglycerol levels were lower in the offspring of Fe-restricted dams at 14 months of age. Although due to variation in the older animals, this was on the borderline of statistical significance $(P=0.055)$. The decreased serum triacylglycerol levels provide an example of an effect on metabolism that is established in the fetus and persists throughout life.

In contrast to our previous findings in these rats at 3 months of age, where glucose tolerance was improved at 14 months of age, there was no difference in glucose tolerance between the maternal diet groups. This may represent a relatively greater rate of deterioration of glucose tolerance in the offspring of Fe-restricted dams compared with those of the control dams. In the offspring of dams fed low-protein diets during pregnancy and lactation, glucose tolerance was improved in younger animals but deteriorated more rapidly, so that by 16 months the offspring of protein-restricted dams were glucose intolerant (Langley et al. 1994; Hales et al. 1996; Shepherd et al. 1997; Langley-Evans et al. 1999b; Petry et al. 2001). It is therefore possible that in even older offspring of $\mathrm{Fe}$ restricted dams glucose intolerance would develop.

It is unclear how the long-term effects of maternal Fe restriction are established in the offspring. Maternal $\mathrm{Fe}$ restriction in the rat has also been shown to alter behaviour in the offspring, possibly due to a decrease in pup brain $\mathrm{Fe}$ content affecting neural development (Felt \& Lozoff, 1996). Tissue Fe deficiency may lead to defects in the development of other systems and contribute to some of the effects observed in the present study. Fe deficiency has been shown to alter the expression of genes involved in its own uptake and whether or not these effects persisted, changes in the expression of these and other genes may permanently affect development (Gambling et al. 2001). Maternal Fe deficiency has been shown to cause increased $\mathrm{Cu}$ absorption into the rat fetus and it is possible that altered levels of $\mathrm{Cu}$ may also affect the development of the offspring (Sherman \& Moran, 1984).

Much of the data collected in the present study were not normally distributed. This may be because in older animals there may be variations in the rate of biological ageing or the rate at which the bodies' systems begin to deteriorate. As a group of animals become older, variations between individuals may become more apparent and this may affect the distribution of the data. In addition, different systems may be affected in different rats, further skewing the distribution.

The present study did not demonstrate a link between the offspring's blood pressure and ACE levels. However, it does provide further evidence for long-term effects of maternal nutrition on the blood pressure and metabolism of offspring and demonstrates that in this model these effects persist throughout the lifespan.

\section{Acknowledgements}

We would like to thank A. Flack, A. Wayman and D. Hutt at the Dunn Nutrition Laboratories for expert 
technical assistance. This work was funded by the Parthenon Trust.

\section{References}

Benediktsson R, Lindsay RS, Noble J, Seckl JR \& Edwards CR (1993) Glucocorticoid exposure in utero: new model for adult hypertension. Lancet 341, 339-341.

Bertram C, Trowern AR, Copin N, Jackson AA \& Whorwood CB (2001) The maternal diet during pregnancy programs altered expression of the glucocorticoid receptor and type 211 betahydroxysteroid dehydrogenase: potential molecular mechanisms underlying the programming of hypertension in utero. Endocrinology 142, 2841-2853.

Crowe C, Dandekar P, Fox M, Dhingra K, Bennet L \& Hanson MA (1995) The effects of anaemia on heart, placenta and body weight, blood pressure in fetal and neonatal rats. Journal of Physiology 488, 515-519.

Desai M, Crowther NJ, Lucas A \& Hales CN (1996) Organselective growth in the offspring of protein-restricted mothers. British Journal of Nutrition 76, 591-603.

Felt BT \& Lozoff B (1996) Brain iron and behavior of rats are not normalized by treatment of iron deficiency anemia during early development. Journal of Nutrition 126, 693-701.

Forhead AJ, Gillespie CE \& Fowden AL (2000) Role of cortisol in the ontogenic control of pulmonary and renal angiotensinconverting enzyme in fetal sheep near term. Journal of Physiology 526, 409-416.

Gambling L, Danzeisen R, Gair S, Lea RG, Charania Z, Solanky N, Joory KD, Srai SK \& McArdle HJ (2001) Effect of iron deficiency on placental transfer of iron and expression of iron transport proteins in vivo and in vitro. Biochemical Journal 356, 883-889.

Hales CN, Desai M, Ozanne SE \& Crowther NJ (1996) Fishing in the stream of diabetes: from measuring insulin to the control. Biochemical Society Transactions 24, 341-350.

Langley SC, Browne RF \& Jackson AA (1994) Altered glucose tolerance in rats exposed to maternal low protein diets in utero. Comparative Biochemistry and Physiology 109, 223-229.

Langley SC \& Jackson AA (1994) Increased systolic blood pressure in adult rats induced by fetal exposure to maternal low protein diets. Clinical Science 86, 217-222.

Langley-Evans SC (1997) Maternal carbenoxolone treatment lowers birthweight and induces hypertension in the offspring of rats fed a protein-replete diet. Clinical Science 93, $423-429$.

Langley-Evans SC \& Jackson AA (1995) Captopril normalises systolic blood pressure in rats with hypertension induced by fetal exposure to maternal low protein diets. Comparative Biochemistry and Physiology 110, A223-A228.

Langley-Evans SC, Sherman RC, Welham SJ, Nwagwu MO, Gardner DS \& Jackson AA (1999a) Intrauterine programming of hypertension: the role of the renin-angiotensin system. Biochemical Society Transactions 27, 88-93.

Langley-Evans SC, Welham SJ \& Jackson AA (1999b) Fetal exposure to a maternal low protein diet impairs nephrogenesis and promotes hypertension in the rat. Life Science 64, 965-974.

Law CM \& Shiell AW (1996) Is blood pressure inversely related to birth weight? The strength of evidence from a systematic review of the literature. Journal of Hypertension 14, 935-941.

Lewis RM, James LA, Zhang J, Byrne CD \& Hales CN (2001a) Effects of maternal iron restriction in the rat on hypoxiainduced gene expression and fetal metabolite levels. British Journal of Nutrition 85, 193-201.

Lewis RM, Petry CJ, Ozanne SE \& Hales CN (2001b) Effects of maternal iron restriction in the rat on blood pressure, glucose tolerance, serum lipids in the 3-month-old offspring. Metabolism 50, 562-567.

Lindsay RM, Edwards CR \& Seckl JR (1996) Inhibition of 11-beta-hydroxysteroid dehydrogenase in pregnant rats and the programming of blood pressure in the offspring. Hypertension 27, 1200-1204.

Lowry OH, Rosenbrough NJ, Farr AL \& Randall RJ (1951) Protein measurement with Folin-phenol reagent. Journal of Biological Chemistry 193, 267-275.

Lucas A, Baker BA, Desai M \& Hales CN (1996) Nutrition in pregnant or lactating rats programs lipid metabolism in the offspring. British Journal of Nutrition 76, 605-612.

Marchand MC \& Langley-Evans SC (2001) Intrauterine programming of nephron number: the fetal flaw revisited. Journal of Nephrology 14, 327-331.

Petry CJ, Dorling MW, Palwak DB, Ozanne SE \& Hales CN (2001) Diabetes in old male offspring of rat dams fed a reduced protein diet. International Journal of Experimental Diabetes Research 2, 139-143.

Rigat B, Hubert C, Alhenc-Gelas F, Cambien F, Corvol P \& Soubrier F (1990) An insertion/deletion polymorphism in the angiotensin I-converting enzyme gene accounting for half the variance of serum enzyme levels. Journal of Clinical Investigation 86, 1343-1346.

Santhamma KR \& Sen I (2000) Specific cellular proteins associate with angiotensin-converting enzyme and regulate its intracellular transport and cleavage-secretion. Journal of Biological Chemistry 275, 23253-23258.

Shepherd PR, Crowther NJ, Desai M, Hales CN \& Ozanne SE (1997) Altered adipocyte properties in the offspring of protein malnourished rats. British Journal of Nutrition 78, $121-129$.

Sherman AR \& Moran PE (1984) Copper metabolism in irondeficient maternal and neonatal rats. Journal of Nutrition 114, 298-306.

Sherman RC \& Langley-Evans SC (1998) Early administration of angiotensin-converting enzyme inhibitor captopril, prevents the development of hypertension programmed by intrauterine exposure to a maternal low-protein diet in the rat. Clinical Science 94, 373-381.

Sherman RC \& Langley-Evans SC (2000) Antihypertensive treatment in early postnatal life modulates prenatal dietary influences upon blood pressure in the rat. Clinical Science 98, 269-275.

Vehaskari VM, Aviles DH \& Manning J (2001) Prenatal programming of adult hypertension in the rat. Kidney International 59, 238-245.

Woodall SM, Johnston BM, Breier BH \& Gluckman PD (1996) Chronic maternal undernutrition in the rat leads to delayed postnatal growth and elevated blood pressure of offspring. Pediatric Research 40, 438-443. 